\title{
UNDERSTANDING WiTHOUT JUSTIFICATION AND BELIEF?
}

\author{
SEUNGBAE PARK
}

\begin{abstract}
Dellsén (2016a) argues that understanding requires neither justification nor belief. I object that ridding understanding of justification and belief comes with the following costs. (i) No claim about the world can be inferred from what we understand. (ii) We run into either Moore's paradox or certain disconcerting questions. (iii) Understanding does not represent the world. (iv) Understanding cannot take the central place in epistemology. (v) Understanding cannot be invoked to give an account of scientific progress. (vi) It is not clear how misunderstanding arises.
\end{abstract}

Keywords: Acceptance; belief; justification; knowledge; Moore’s paradox; understanding.

\section{Introduction}

Understanding is an important part of our mental life. If our best current scientific theories are true, we understand why an earthquake occurs, why the Earth moves around the Sun, and why an electron has mass. Many epistemologists and philosophers of science these days are interested in the nature of understanding. Some philosophers (Kitcher 2002; Lipton 2004; Grimm 2006; 2014) argue that just as knowledge requires justification and belief, so understanding requires them as well. By contrast, Finnur Dellsén (2016a) argues that understanding requires neither justification nor belief. The aim of this paper is to raise issues against Dellsén's conception of understanding.

The outline of this paper is as follows. In Section 2, I critically respond to Dellsén's example that is intended to show that understanding does not require justification, arguing that if understanding is devoid of justification, no claim about the world can be inferred from what we understand. In Section 3, I critically respond to Dellsén's example that is intended to show that understanding requires not belief but acceptance, arguing that if Dellsén is right, we run into either Moore's paradox or certain disconcerting questions. Further problems with Dellsén's conception of understanding are that contrary to what he says, understanding is not about the world, cannot take the place of knowledge in epistemology, and cannot be invoked to give an account of scientific progress. Finally, I point out that it is not clear how misunderstanding arises.

Principia 21(3): 379-389 (2017).

Published by NEL — Epistemology and Logic Research Group, Federal University of Santa Catarina (UFSC), Brazil. 


\title{
2. No Justification
}

This section examines an example that Dellsén has provided to argue that "understanding does not require justification" (Dellsén 2016a, p.4). The example concerns Bernie, a retired automobile mechanic living in a rural area. He has good reason to believe that a con man's testimony is untrustworthy, but acquires some understanding as a result of attending to the con man's testimony:

\begin{abstract}
Case 2. Bernie is a retired automobile mechanic living in a very small town in rural America. One morning Bernie reads in the local newspaper that a convicted confidence man is coming to town. The story included a picture of the man and the following warning: 'This man will try to scam you, so don't believe a word he says'. The next day, the con man is driving past Bernie's house when his car suddenly breaks down. The con man rings on Bernie's doorbell, and Bernie opens the door. Recognizing the con man face from the newspaper, Bernie decides to stay inside his house while conversing with the con man. The con man tells Bernie what appears to be wrong with the car and solicits Bernie's assistance. Based only on the con man's description of the car's behavior immediately before the breakdown (all of which is accurate), Bernie immediately diagnoses the problem as a broken timing belt (which is correct). Yet Bernie is not justified in believing this, since he should know better than to trust a convicted con man. (Dellsén 2016a, p.5)
\end{abstract}

This example is intended to show that Bernie is not justified in believing that the con man's car does not work, that the con man's description of the car's symptoms is true, and that the timing belt is broken, but to show additionally that "Bernie clearly understands what's wrong with the con man's car” (Dellsén 2016a, p.8).

Let me make what I take to be an important point with respect to the example above. Suppose that Bernie had the following conversation with his philosophical opponent, Bob:

Bob: Please state the understanding you just acquired from what the con man said.

Bernie: The con man's car doesn't work because the timing belt is broken.

Bob: Are you justified in believing the con man's car doesn't work, or the timing belt is broken?

Bernie: No, I'm not.

Bob: If so, how can you say to me the con man's car doesn't work because the timing belt is broken? Do you expect me to believe what you are not justified in believing?

Bernie: Oh, let me put my position more precisely. I don't know whether the con man has a car or not, whether his car works or not, and whether the timing belt is broken or not. That is not important for my understanding of the possible problem with his car. From what he said, I can understand what might have happened, i.e., it might be that the con man's car is broken

Principia 21(2): 379-389 (2017). 
because the timing belt is broken.

Bob: If so, you are not justified in believing that your understanding agrees with a state of affairs, i.e., in believing that what you understand reflects the world.

Dellsén might be right that "Bernie clearly understands what's wrong with the con man's car" (Dellsén 2016a, p.6). But it is merely an accident that what Bernie understands corresponds to the state of affairs that the con man's car is broken. In other words, Bernie is not justified in believing that what he understands reflects the world. Accordingly, he cannot make an inference about the world. He cannot infer, for example, that he has an opportunity to make some money by fixing the car, or that he would see the car once he steps out of his house. How can he make such inferences when he does not even believe that there is a car outside of his house? Only an irrational person would make such inferences. By contrast, if Bernie is justified in believing that the con man's car does not work because the timing belt is broken, he is justified in inferring that he has an opportunity to make some money by fixing the car, and that he can see the car once he steps out of his house. In short, if Dellsén is right that understanding is devoid of justification, we cannot make any inference about the world from what we understand, and understanding cannot help us guide our actions in the world.

\section{No Belief}

Dellsén (2016a, pp.10-11) claims that understanding requires not belief but acceptance, appealing to L. Jonathan Cohen's (1992) distinction between belief and acceptance. For Cohen, to believe that $p$ is to be disposed to feel that it is true, whereas to accept that $p$ is to adopt the policy of including $p$ "among one's premises for deciding what to do or think in a particular context" (1992, p.4). To use his example, a defense attorney may accept that his client is innocent, although he believes that his client is guilty. To accept that his client is innocent means to use the proposition that his client is innocent as a premise for deciding what to think and what to speak in court. If he accepts that his client is innocent, the way he speaks in court is exactly the same as the way he would have spoken if he believed that his client was innocent. In other words, there is no verbal difference between a person who accepts that $p$ and another person who believes that $p$ in a particular context.

Dellsén argues that "understanding something may merely involve treating certain propositions or theories as given in the context of explaining something, as opposed to being disposed to feel that the propositions or theories are true" (2016a, p.10). For example, Carrie, a theoretical physicist, does not believe that string theory is true, but she accepts that it is true. Even if she merely accepts that it is true, she

Principia 21(2): 379-389 (2017). 
can use "it in explanations of various natural phenomena" (2016a, p.11):

In this case, it seems clear that Carrie understands the fundamental structure of her world that string theory is meant to describe. After all, Carrie can use the theory to explain any fundamental physical phenomena just as well as someone who also believes string theory (and better than someone who does not accept string theory. (Dellsén 2016a, p.11)

So it does not matter whether Carrie believes or merely accepts that string theory is true. She can use it to explain and understand the fundamental structure of the world. Dellsén, however, does not specify how Carrie can explain and understand the fundamental structure of the world that string theory is meant to describe.

Let me specify how Carrie might explain and understand the fundamental structure of the world in terms of string theory. According to string theory, everything is ultimately made out of tiny filaments of energy called strings. Strings vibrate in different frequencies, which are responsible for the existence of different particles: electrons, quarks, photons, and gravitons. The way strings vibrate is determined by the geometry of extra dimensions. The extra dimensions are so small that we cannot see them. String theory requires eleven dimensions: one dimension of time and ten dimensions of space. No experiment has yet been performed to test string theory.

Scientists, however, believe that a particle accelerator could be used to confirm string theory. Imagine that two particles move in opposite directions at nearly the speed of light and collide with each other. Imagine also that the amount of energy after the collision is smaller than the amount of energy before the collision. Such an experimental result would confirm string theory because it can be explained by the hypothesis that some energy is forced into the extra dimensions.

Is it plausible that Carrie can explain and understand the fundamental structure of the world in terms of string theory by merely accepting that string theory is true? My answer is no. Imagine that the experiment depicted above is performed, that the expected outcome obtains, and that Carrie has the following conversation with her philosophical opponent, Bob:

Bob: Do you understand why the amount of energy after the collision is smaller than that of energy before the collision?

Carrie: Yes, I do. The amount of energy after the collision is smaller than that of energy before the collision because some energy is forced into the extra dimensions.

Bob: Do you believe the amount of energy after the collision is smaller than that of energy before the collision because some energy is forced into the extra dimensions?

Carrie: No, I don't. But I accept the amount of energy after the collision is smaller than that of energy before the collision because some energy is forced into the extra dimensions.

Principia 21(2): 379-389 (2017). 
Bob: Even if you merely accept that, you are caught in Moore's paradox. Your sentence has the form: $p$, but I don't believe that $p$, although I accept that $p$. It contains a Moorean sentence: $p$, but I don't believe that $p$ (Park 2016, pp.77-79).

Moore's paradox occurs when we assert a sentence of the form, " $P$, but I don't believe $p$ " or " $P$, but I believe not $p$ " (Moore 1993, pp.207-212). Carrie in effect said above, "The amount of energy after the collision is smaller than that of energy before the collision because some energy is forced into the extra dimensions, but I don't believe the amount of energy after the collision is smaller than that of energy before the collision because some energy is forced into the extra dimensions". So she is caught in Moore's paradox. Researchers on Moore's paradox agree that it is absurd to assert a Moorean sentence, and that the absurdity originates from a contradiction, but they disagree over wherein the contradiction lies (Park 2014, p.345).

What is important for the purpose of this paper is that we run into Moore's paradox when we express what we understand and then declare that we do not believe what we understand. It appears, therefore, that to avoid Moore's paradox, we should believe what we understand. Thus, if you eliminate belief from understanding, you owe us an account of how you can avoid Moore's paradox.

Carrie might try to circumvent Moore's paradox by not declaring that she does not believe what she understands, i.e., by not saying to Bob, "I don't believe the amount of energy after the collision is smaller than that of energy before the collision because some energy is forced into the extra dimensions". This move, however, invites a different sort of objection. Bob could then ask Carrie some disconcerting questions (Park 2018, Section 4): "Do you believe the amount of energy after the collision is smaller than that of energy before the collision because some energy is forced into the extra dimensions? If not, how can you say to me what you don't believe? Do you expect me to believe what you don't? Why should I believe what you don't?" Thus, if belief is not a requirement of understanding, we run into either Moore's paradox or these disconcerting questions. Cohen's notion of acceptance cannot rescue Bernie from Moore's paradox or such disconcerting questions. ${ }^{1}$

Let me raise a different sort of objection to Dellsén's contention that understanding does not require belief. It is a double standard to believe that an explanandum is true while merely accepting that an explanans is true. We ought to treat an explanandum and an explanans consistently, which requires that we believe both the explanandum and the explanans, or that we merely accept both the explanandum and the explanans. So Carrie ought not to believe but merely accept that the amount of energy after the collision is smaller than that of energy before the collision. If she believes that the explanandum is true, she owes us an account of why she treats the explanans and the explanandum differently. The same point applies to the previous example of the defense attorney. Given that he merely accepts that his client is inno- 
cent, and then infers that his client was not at the crime scene, he should also merely accept that his client was not at the crime scene. In sum, it is illegitimate to merely accept some propositions while believing other propositions.

To merely accept all propositions involved in an understanding means that the understanding does not represent the world, i.e., it has nothing to do with the world. This corollary is obvious, once we consider the fundamental difference between belief and acceptance. A belief is a mental state that is either true or false, depending on whether it correctly or incorrectly represents the world. By contrast, an acceptance is not a mental state that can be true or false, i.e., it is not a mental state that represents the world. Recall that to accept a proposition is to adopt the policy of using the proposition as a premise, to use Cohen's (1992, p.4) expression, or to treat the proposition as given, to use Dellsén's (2016a, p.10) expression. Adopting a policy or treating a proposition can neither be true nor be false. It can at best be useful or useless. For example, the defense attorney's acceptance that his client is innocent can be useful or useless, depending on whether it helps to win his case. The acceptance would be useless if the prosecutor presents undeniable proof that the defendant is guilty. Thus, if acceptance, as opposed to belief, is an essential ingredient of understanding, understanding does not represent the world, and hence it does not even give us a clue as to what the world looks like.

This point can be illustrated by an example. Imagine that two children have the following quarrel over two imaginary figures, Superman and Batman:

Child 1: Who wins if Superman and Batman fight with each other?

Child 2: Of course, Superman wins. After all, he can lift up a heavy rock as

large as a mountain. Moreover, he can fly. But Batman can do none of these things.

Child 1: No, Batman wins. He only needs to carry Kryptonite.

Child 2: I understand.

Both children understand how Batman can beat Superman. They do not, however, believe that Superman and Batman are real, and hence that Kryptonite makes Superman powerless. They merely accept these propositions, i.e., they merely use them as premises for the conclusion that Batman could beat Superman. The inference from the premises to the conclusion gives rise to the understanding of how Batman could beat Superman.

The children's understanding fits Dellsén's conception of understanding, but does not represent the world. The children know that Batman and Superman are not real. They do not feel that the propositions about Batman and Superman are true. But they understand how Batman can defeat Superman. Their understanding does not imply that they have an insight into the world, or that they understand how the world works. To generalize, if acceptance, as opposed to belief, is an ingredient of 
understanding, to understand why $p$ is merely a matter of grasping some propositions independently of the way the world operates. Such a mental state cannot accurately guide our actions in the world.

By contrast, suppose that the standard model of particle physics is true, that particle physicists believe that it is true, and hence they believe that a particle has mass because it interacts with the Higgs field. Under such conditions, particle physicists understand why a particle has mass, their understanding is about the world, and it contains an insight into the world. Moreover, since their understanding reflects the world, it can guide their actions in the world. Of course, the standard model of particle physics might be false, but if it is false, then particle physicists do not understand but rather misunderstand why a particle has mass.

Dellsén says that "Carrie understands the fundamental structure of her world that string theory is meant to describe" (2016a, p.11). Such a locution indicates that Dellsén takes understanding to be about the world, i.e., he believes that understanding represents the world. It is not clear, however, how he can say so when he claims that understanding is free of belief. It is not clear how Carrie can understand the fundamental structure of the universe that the string theory is meant to describe by merely accepting it. It claims that the universe has extra dimensions. Carrie uses the proposition that the universe has the extra dimensions as a premise for her inferences. But she does not believe that the universe has the extra dimensions. Under such a condition, Carrie does not understand the fundamental structure of the world that string theory is meant to describe. The fundamental structure of the universe lies beyond the scope of her understanding. Of course, this does not mean that she does not have any understanding at all. She has an understanding in that she grasps how the propositions of string theory are related to one another. Such an understanding has nothing to do with the world. The same criticism applies to the example of Bernie and the con man. Dellsén claims that "Bernie clearly understands what's wrong with the con man's car" (2016a, p.6). Again, such a locution indicates that Dellsén takes understanding to reflect the world. Notice, however, that Bernie does not even believe that the con man has a car. If so, it is not clear how Dellsén can say that Bernie clearly understands what is wrong with the con man's car. Bernie merely accepts that the con man has a car, that his car does not work, and that the timing belt is broken. He merely uses these propositions for his inference that if the car were broken, that would be because the timing belt is broken. The problem with the con man's car, the state of affairs, lies beyond the scope of Bernie's understanding.

In the face of my preceding criticism, Dellsén might distinguish between understandings that represent the world and understandings that do not represent the world, and then claim that belief is an essential component of the former, but not of the latter. An example of understanding that represents the world would be physicists' understanding of the structure of spacetime, on condition that the general theory of 
relativity is true, and on condition that they believe that it is true. An example of understanding that does not represent the world would be the children's understanding of how Batman can beat Superman. The propositions about Batman and Superman are false, and the children do not believe that they are true.

A problem with the preceding move is that it is a mistake to rid understanding of belief, and then to claim that understanding represents the world. For example, it would be a mistake for Dellsén to say that Carrie merely accepts string theory, and then to claim that she has an understanding of the fundamental structure of the world. How can she understand the fundamental structure of the world when she does not even believe that the fundamental structure of the world is real? She only understands how the propositions of string theory are related to one another, just as the children understand how the propositions about Superman and Batman are related to one another. Her understanding and the children's understanding do not reflect the world at all, i.e., their understandings do not contain information about the world. It follows that they cannot make any inference about the world from what they understand.

Let me raise another objection to Dellsén's conception of understanding. It is not clear how misunderstanding arises under his framework. If acceptance is an essential ingredient of understanding, it is problematic to say that understanding arises when its constituent acceptance is true, and that misunderstanding arises when its constituent acceptance is false. As already said, an acceptance is not a mental state that is capable of being true or false. By contrast, if belief is an essential component of understanding, we can say that understanding arises when its constituent belief is true, and that misunderstanding arises when its constituent belief is false.

Let me flesh out the preceding objection with an example. According to Aristotelian mechanics, an apple falls down because it has the purpose of returning to its natural place, which is the center of the universe. Obviously, Aristotelians misunderstood why the apple fell down. There can be two different explanations of why they misunderstood the phenomena. The first one holds that they misunderstood the phenomena because they accepted Aristotelian mechanics and their acceptance was false. The second one holds that they misunderstood the phenomenon because they believed Aristotelian mechanics and their belief was false. The first explanation is problematic, whereas the second one is not.

Let me elucidate two implications of my preceding criticisms against Dellsén's conception of understanding. First, Dellsén cites the view that "understanding should replace knowledge as the primary focus of epistemology" (2016a, p.1). This view is defended by Linda Zagzebski (2001), Jonathan Kvanvig (2003), Catherine Elgin (2006), and Duncan Pritchard (2010). It seems to me, however, that knowledge has traditionally taken the central place in epistemology because it is a mental state that is connected with the world. Epistemologists' interest in knowledge stems from their

Principia 21(2): 379-389 (2017). 
interest in what the world looks like, and what we can do with the use of knowledge. If, however, understanding is a mental state that is disconnected from the world, it is not clear why it should take the central place in epistemology. Knowledge is power, but understanding is not, if Dellsén is right that understanding is devoid of justification and belief.

Dellsén's view on the place of understanding in epistemology is slightly different from the one that he cites above. He says that "knowledge and understanding should coexist as two separate focus points for epistemology" (Dellsén 2016a, p.14). My response to this view is to admit that knowledge and understanding can coexist in epistemology, but to add that understanding is not as important as knowledge in epistemology for the reason stated above, viz., knowledge is power, whereas understanding is not. To go further, the task of investigating the nature of understanding can be undertaken not by epistemologists but by philosophers of mind.

Second, philosophers of science advance various accounts of scientific progress. They claim that scientific progress consists in the accumulation of knowledge (Bird 2007; Park 2017), the increase in verisimilitude (Niiniluoto 1980; 2014), the increase in problem-solving capabilities (Kuhn 1962[1970]; Laudan 1977; 1984), and “in increasing understanding" (Dellsén 2016b, p.73). Dellsén's idea is that as science progresses, we come to understand the world more and more. For example, scientific progress was made when Newtonian mechanics was replaced by Einsteinian mechanics, and we understand more about the world as a result of the replacement of Newtonian mechanics with Einsteinian mechanics. If, however, understanding does not represent the world, it is problematic to say that as science progresses, we come to understand the world more and more. Consider also that as science progresses, we can control more and more parts of the world. It is not clear how Dellsén's account of scientific progress can accommodate this aspect of scientific progress. Recall that his account of understanding entails that understanding does not help us guide our actions.

\section{Conclusion}

Dellsén argues that understanding requires neither justification nor belief. Ridding understanding of justification and belief, however, comes with the following costs. No inference about the world can be made from what we understand. We run into either Moore's paradox or certain disconcerting questions. Understanding does not represent the world, contrary to what Dellsén says, and therefore can neither take the central place in epistemology nor be invoked to account for scientific progress. Finally, it is not clear how misunderstanding arises. In sum, no belief about the world? No understanding about the world! No justified belief about the world? No inference about the world!

Principia 21(2): 379-389 (2017). 


\section{Acknowledgments}

I thank anonymous referees of this journal for useful comments. This work was supported by the Ministry of Education of the Republic of Korea and the National Research Foundation of Korea (NRF-2016S1A5A2A01022592).

\section{References}

Bird, A. 2007. What is Scientific Progress? Noûs 41(1): 64-89.

Cohen, L. J. 1992. An Essay on Belief and Acceptance. Oxford: Oxford University Press.

Dellsén, F. 2016a. Understanding without Justification or Belief. Ratio, DOI: $10.1111 /$ rati.12134.

2016b. Scientific Progress: Knowledge vs. Understanding. Studies in History and Philosophy of Science 56: 72-83.

Elgin, C. 2006. From Knowledge to Understanding. In: S. Hetherington (ed.) Epistemology Futures. Oxford: Oxford University Press.

Grimm, S. 2006. Is Understanding a Species of Knowledge? The British Journal for the Philosophy of Science 57(3): 515-535.

- 2014. Understanding as Knowledge of Causes. In: A. Fairweather (ed.) Virtue Epistemology Naturalized: Bridges between Virtue Epistemology and Philosophy of Science, pp.329-345. Cham: Springer.

Kitcher, P. 2002. Scientific Knowledge. In: P. Moser (ed.) The Oxford Handbook of Epistemology, pp.385-408. New York: Oxford University Press.

Kuhn, T. 1962[1970]. The Structure of Scientific Revolutions. Chicago: University of Chicago Press.

Kvanvig, J. 2003. The Value of Knowledge and the Pursuit of Understanding. New York: Cambridge University Press.

Laudan, L. 1977. Progress and Its Problems. London: Routledge and Kegan Paul.

- 1984. Science and Values. Berkeley: University of California Press.

Lipton, P. 2004. Inference to the Best Explanation. New York: Routledge.

Moore, G. 1993. Moore's Paradox. In: T. Baldwin (ed.) G. E. Moore: Selected Writings. London: Routledge.

Niiniluoto, I. 1980. Is Science Progressive? Dordrecht: Reidel.

- 2014. Scientific Progress as Increasing Verisimilitude. Studies in History and Philosophy of Science 46: 73-77.

Park, S. 2014. On the Relationship between Speech Acts and Psychological States. Pragmatics and Cognition 22(3): 340-351.

— 2015. Accepting Our Best Scientific Theories. Filosofija. Sociologija 26(3): 218-227.

- 2016. Scientific Realism and Antirealism in Science Education. Coactivity: Philosophy. Communication 24(1): 72-81.

- 2017. Does Scientific Progress Consist in Increasing Knowledge or Understanding? Journal for General Philosophy of Science 48(4): 569-579.

—. 2018. Should Scientists Embrace Scientific Realism or Antirealism? Philosophical Forum (to be assigned).

Principia 21(2): 379-389 (2017). 
Pritchard, D. 2010. Knowledge and Understanding. In: A. Haddock; A. Miller; D. Pritchard (eds.) The Nature and Value of Knowledge: Three Investigations, pp.3-90. New York: Oxford University Press.

Zagzebski, L. 2001. Recovering Understanding. In: M. Steup (ed.) Knowledge, Truth, and Duty: Essays on Epistemic Justification, Responsibility, and Virtue. New York: Oxford University Press.

SEungbae PARK Associate Professor Division of General Studies Ulsan National Institute of Science and Technology Ulju-gun, Ulsan 689-798 REPUBLIC OF KOREA nature@unist.ac.kr

\section{Notes}

${ }^{1}$ There are further problems with explaining an explanandum by merely accepting an explanans. It is unethical to do so in certain social contexts (Park 2015, pp.225-228). Moreover, if scientists merely accept their data, they are opening themselves to the accusation that they have fabricated them (Park 2017, pp.2-3).

Principia 21(2): 379-389 (2017). 